BERGAMIN, L.G.; CRUZ, M.C.P.; FERREIRA, M.E.; BARBOSA, J.C. Produção de repolho em função da aplicação de boro associada a adubo orgânico. Horticultura Brasileira, Brasília, v.23, n.2, p.311-315, abr-jun 2005.

\title{
Produção de repolho em função da aplicação de boro associada a adubo orgânico
}

\author{
Luis Guilherme Bergamin; Mara Cristina P. da Cruz; Manoel Evaristo Ferreira; José Carlos Barbosa \\ FCAV-UNESP, Via de Acesso Prof. Paulo Donato Castellane s/nº, 14884-900 Jaboticabal-SP; E-mail: evaristo@fcav.unesp.br
}

\section{RESUMO}

Em condições de campo, em solo argiloso com teor médio de boro, foram avaliados os efeitos da adubação com boro, associada à adubação orgânica, na produção de repolho híbrido Kenzan. Cinco doses de B $\left(0 ; 2,0 ; 4,0 ; 6,0\right.$ e 8,0 $\left.\mathrm{kg} \mathrm{ha}^{-1}\right)$ foram associadas, em esquema fatorial, à ausência e presença $\left(0 \mathrm{e} 10 \mathrm{t} \mathrm{ha}^{-1}\right)$ de vermicomposto de esterco bovino. O delineamento experimental foi em blocos casualizados com três repetições e as adubações orgânica e química foram feitas no sulco, por ocasião do transplantio das mudas. O ponto de colheita foi atingido 75 a 90 dias após o transplantio. A adubação com vermicomposto de esterco de bovino elevou a produção em 3,8 $\mathrm{t}$ ha ${ }^{-1}$, o diâmetro das cabeças de repolho em $0,8 \mathrm{~cm}$ e o peso das cabeças em $170 \mathrm{~g}$. A produção de repolho aumentou linearmente com a adubação com B e variou de 52,94 t ha-1 a 65,95 $\mathrm{t} \mathrm{ha}^{-1}$. A relação entre B no solo e produção foi linear e positiva.

Palavras-chave: Brassica oleraceae var. capitata, vermicomposto de esterco de bovino.

\section{ABSTRACT}

Cabbage yield in relation to boron fertilization associated with organic manure

A field experiment was carried out in a clayey soil to determine the effects of boron fertilizer and organic manure on 'Kenzan' cabbage yield. The treatments consisted of $0 ; 2,0 ; 4,0 ; 6,0$ and 8,0 $\mathrm{kg} \mathrm{ha}^{-1} \mathrm{~B}$ and presence $\left(10 \mathrm{t} \mathrm{ha}^{-1}\right)$ and absence of cattle manure vermicompost (CMV) arranged in a factorial scheme $(5 \times 2)$. The experimental design was of randomized blocks, with three replications. The organic and chemical fertilization was applied in bands, before the seedlings transplant, and the harvest was done 75 to 90 days after transplant. The CMV application increased the cabbage yield in $3.8 \mathrm{t} \mathrm{ha}^{-1}$, the diameter in $0.8 \mathrm{~cm}$ and the cabbage weight in $170 \mathrm{~g}$. The cabbage yield increased linearly with boron application and ranged from $52.94 \mathrm{t} \mathrm{ha}^{-1}$ to $65.95 \mathrm{t} \mathrm{ha}^{-1}$. The relation between soil $\mathrm{B}$ and yield was linear and positive.

Keywords: Brassica oleraceae var. capitata, cattle manure vermicompost.

\section{(Recebido para publicação em 13 de fevereiro de 2004 e aceito em 11 de março de 2005)}

E ntre as hortaliças mais ricas em boro estão a beterraba, a cenoura, o rabanete e as brássicas. No grupo das brássicas o repolho, a couve-flor e o brócolos são as mais consumidas, sendo o repolho classificado como de média exigência em boro (MARTENS; WESTERMANN, 1991).

A adubação com boro para brássicas no Brasil é recomendada com freqüência, tendo em vista que os resultados existentes indicam resposta positiva para utilização deste micronutriente. Alvares et al. (1985) avaliando a resposta do repolho, híbrido Matsukaze, à aplicação de $0 ; 1 ; 3 ; 5$ e $10 \mathrm{~kg} \mathrm{ha}^{-1}$ de $\mathrm{B}$, em LATOSSOLO VERMELHO-AMARELO com teor inicial de $0,38 \mathrm{mg} \mathrm{kg}^{-1}$ de B extraído com água quente, observaram que para atingir produção máxima (100\%), 97\% e 85\% dela, seriam necessários, respectivamente, 7,18; 5,0 e 1,78 kg $\mathrm{ha}^{-1}$ de $\mathrm{B}$ e as produções corresponderiam a 44,5; 43,2 e 37,8 $\mathrm{t} \mathrm{ha}^{-1}$. Os teores de B no solo que resultaram em 85 e $100 \%$ da produção máxima foram 1,0 e $1,5 \mathrm{mg} \mathrm{kg}$ ${ }^{1} \mathrm{e}$, nas folhas, 24,4 e $38,2 \mathrm{mg} \mathrm{kg}^{-1}$, res- pectivamente. As plantas que não receberam boro apresentavam cabeças frouxas e a sua compacidade aumentou com as doses de $\mathrm{B}$.

Em solos não adubados com boro, a matéria orgânica é uma das fontes mais importantes do nutriente. Prova disso está no fato de que a ocorrência de deficiência está normalmente associada a solos arenosos, pobres em matéria orgânica e ácidos. Carneiro et al. (1985) obtiveram efeito da adubação com boro para repolho apenas nos tratamentos sem adubação orgânica e a máxima produção teórica foi obtida com a aplicação de cerca de $11,5 \mathrm{~kg} \mathrm{ha}^{-1}$ de B.

Coutinho et al. (1999) obtiveram produção máxima de repolho $\left(46,8 \mathrm{t} \mathrm{ha}^{-1}\right)$ em um LATOSSOLO VERMELHOESCURO textura média, com V=29\% e $\mathrm{B}$ extraído com $\mathrm{BaCl}_{2}$ de $0,30 \mathrm{mg} \mathrm{dm}{ }^{-3}$, com aplicação de $4 \mathrm{~kg} \mathrm{ha}^{-1}$ de $\mathrm{B}$ na presença e na ausência de calagem. Em ambas as situações houve decréscimo de produção com a aplicação de $12 \mathrm{~kg} \mathrm{ha}^{-1}$ de B. As concentrações de B no solo e nas folhas aumentaram significativa- mente com as doses aplicadas e uma produção relativa igual a $90 \%$ foi associada às concentrações de $0,53 \mathrm{mg} \mathrm{dm}^{-3}$ no solo e $20 \mathrm{mg} \mathrm{kg}^{-1}$ nas folhas.

Atualmente, no estado de São Paulo são recomendados 3 a $4 \mathrm{~kg} \mathrm{ha}^{-1}$ de B no plantio para brócolos, couve-flor e repolho, mais três aplicações foliares ( $1 \mathrm{~g}$ $\mathrm{L}^{-1}$ de B) durante o ciclo, sem levar em conta o teor de boro do solo (TRANI et al., 1996).

O objetivo desse trabalho foi avaliar os efeitos da adubação com boro, na presença e ausência de vermicomposto de esterco bovino, na produção de repolho.

\section{MATERIAL E MÉTODOS}

$\mathrm{O}$ experimento foi conduzido no município de Nova Europa (SP), de junho a outubro de 2001, em LATOSSOLO VERMELHO Eutroférrico, com as seguintes características na camada de 0 a $20 \mathrm{~cm}$ : $\mathrm{P}$ resina $=112 \mathrm{mg} \mathrm{dm}^{-3} ;$ M.O. $=37 \mathrm{~g} \mathrm{dm}^{-3} ; \mathrm{pH}$ em $\mathrm{CaCl}_{2}=5,3 ; \mathrm{K}=9,6 \mathrm{mmol}_{\mathrm{c}} \mathrm{dm}^{-3} ; \mathrm{Ca}$ 
$=61 \mathrm{mmol} \mathrm{dm}^{-3} ; \mathrm{Mg}=18 \mathrm{mmol}_{\mathrm{c}} \mathrm{dm}^{-3} ; \mathrm{H}$ $+\mathrm{Al}=38 \mathrm{mmol} \mathrm{dm}^{-3} ; \mathrm{SB}=89 \mathrm{mmol} \mathrm{dm}^{\mathrm{c}}$ 3; $\mathrm{CTC}=127 \mathrm{mmol} \mathrm{dm}^{-3} ; \mathrm{V}=70 \% ; \mathrm{B}=$ $0,26 \mathrm{mg} \mathrm{dm}^{-3} ; \mathrm{Cu}=22,9 \mathrm{mg} \mathrm{dm}^{-3} ; \mathrm{Fe}=42$ $\mathrm{mg} \mathrm{dm}{ }^{-3} ; \mathrm{Mn}=91,1 \mathrm{mg} \mathrm{dm}^{-3} ; \mathrm{Zn}=6,0 \mathrm{mg}$ $\mathrm{dm}^{-3}$; e $\mathrm{S}_{-} \mathrm{SO}_{4}{ }^{2-}=10 \mathrm{mg} \mathrm{dm}{ }^{-3}$. A análise básica foi feita seguindo a metodologia descrita em Raij et al. (1987); o boro foi extraído em solução de $\mathrm{BaCl}_{2}$ 1,25 g L-1 em forno de microondas (ABREU et al., 1994); cobre, ferro, manganês e zinco foram extraídos com solução de DTPA 0,005 mol L-1 (LINDSAY; NORVELL, 1978); e o enxofre foi extraído com solução de $\mathrm{Ca}\left(\mathrm{H}_{2} \mathrm{PO}_{4}\right)_{2} \quad 0,01 \quad \mathrm{~mol} \quad \mathrm{~L}^{-1}$ (CANTARELLA; PROCHNOW, 2001). $\mathrm{O}$ vermicomposto de esterco de bovino empregado foi caracterizado segundo a metodologia descrita por Kiehl (1985) e Tedesco et al. (1985) e apresentava: $\mathrm{pH}$ em $\mathrm{CaCl}_{2}=6,3 ; \mathrm{C}=158 \mathrm{~g} \mathrm{~kg}^{-1} ; \mathrm{N}=11 \mathrm{~g} \mathrm{~kg}^{-1}$; $\mathrm{P}=3 \mathrm{~g} \mathrm{~kg}^{-1} ; \mathrm{K}=3 \mathrm{~g} \mathrm{~kg}^{-1} ; \mathrm{Ca}=7 \mathrm{~g} \mathrm{~kg}^{-1} ; \mathrm{Mg}$ $=3 \mathrm{~g} \mathrm{~kg}^{-1} ; \mathrm{B}=10 \mathrm{mg} \mathrm{kg}^{-1} ; \mathrm{Cu}=162 \mathrm{mg} \mathrm{kg}^{-}$ ${ }^{1} ; \mathrm{Fe}=68236 \mathrm{mg} \mathrm{kg}^{-1} ; \mathrm{Mn}=742 \mathrm{mg} \mathrm{kg}^{-1}$; $\mathrm{Zn}=204 \mathrm{mg} \mathrm{kg}^{-1}$.

O delineamento experimental empregado foi blocos casualizados, com os tratamentos distribuídos em esquema fatorial $5 \times 2$, com os fatores doses de boro $\left(0,0 ; 2,0 ; 4,0 ; 6,0\right.$ e $\left.8,0 \mathrm{~kg} \mathrm{ha}^{-1}\right)$, na forma de bórax, e presença e ausência de vermicomposto de esterco de bovino (0 e 10 t ha $^{-1}$, peso seco), em três repetições.

A parcela foi constituída por sete linhas de repolho com 5,0 m de comprimento; o espaçamento foi de $0,80 \mathrm{~m} \mathrm{x}$ $0,50 \mathrm{~m}$, tomando-se as três linhas centrais como úteis, das quais foram desconsideradas as duas plantas de cada extremidade.

Inicialmente, produziu-se as mudas de repolho, híbrido Kenzan. Aos 38 dias após a semeadura, quando se apresentavam com aproximadamente $15 \mathrm{~cm}$ de altura e com cinco a seis folhas definitivas, foram transplantadas.

A calagem foi feita 80 dias antes do transplantio com o objetivo de elevar o índice de saturação por bases do solo a $80 \%$, por meio da aplicação de $1,4 \mathrm{t} \mathrm{ha}^{-1}$ de calcário dolomítico (PRNT 91\%), o qual foi distribuído a lanço, em área total, e incorporado por meio de aração e gradagem. Por ocasião do transplantio foram abertos sulcos de 20 a $25 \mathrm{~cm}$ de profundidade para a aplicação dos adubos. O adubo orgânico foi aplicado no fundo do sulco e incorporado levemente com enxada e, em seguida, o bórax foi aplicado no mesmo sulco, juntamente com a adubação NPKS, baseada na análise de solo e na recomendação de Trani et al. (1996). Foram utilizados $60 \mathrm{~kg} \mathrm{ha}^{-1} \mathrm{de}$ $\mathrm{N}, 200 \mathrm{~kg} \mathrm{ha}^{-1}$ de $\mathrm{P}_{2} \mathrm{O}_{5}$ e $120 \mathrm{~kg} \mathrm{ha}^{-1} \mathrm{de}$ $\mathrm{K}_{2} \mathrm{O}$, como sulfato de amônio, superfosfato triplo e cloreto de potássio.

Foi feito controle de plantas invasoras por meio de capinas manuais, e controle pragas (traça das crucíferas e curuquerê da couve), com aplicação de inseticidas organofosforados e piretróides, em aplicações alternadas.

Quinze dias após o transplantio das mudas foi feita pulverização foliar com solução contendo $0,5 \mathrm{~g} \mathrm{~L}^{-1}$ de molibdato de amônio e, nas adubações em cobertura, foram aplicados $150 \mathrm{~kg} \mathrm{ha}^{-1}$ de $\mathrm{N}$ (sulfato de amônio) e $60 \mathrm{~kg} \mathrm{ha}^{-1} \mathrm{~K}_{2} \mathrm{O}$ (cloreto de potássio), parcelados em quatro vezes durante o ciclo da cultura, de acordo com a recomendação de Trani et al. (1996). A irrigação foi feita por sulco aberto no meio das entrelinhas.

Para determinação do teor de boro nas folhas do repolho foi feita amostragem da folha envoltórias das cabeças das 21 plantas da área útil de cada parcela, no início da formação da cabeça (cerca de 30 dias após o transplantio), conforme recomendado por Trani e Raij (1996). As amostras foram lavadas, secadas e moídas para determinação de boro segundo Bataglia et al. (1983).

Quando as plantas atingiram o ponto de colheita, cerca de 75 a 90 dias após o transplantio, foi obtida a produção por parcela e o diâmetro da cabeça.

Após a colheita foi feita amostragem de solo, parcela por parcela, para análisar o teor de boro. Cada amostra foi obtida de 20 subamostras e a coleta foi feita na linha de plantio.

Os efeitos dos tratamentos na produção de repolho, nos teores de boro na folha e no solo foram avaliados por meio de análise de variância; os efeitos da adubação orgânica foram comparados pelo teste de Tukey e as doses de boro foram estudadas por análises de regressão.

\section{RESULTADOS E DISCUSSÃO}

Na Tabela 1 estão apresentados os resultados obtidos para teor de boro nas folhas e no solo, produção, peso e diâmetro das cabeças de repolho. Como não foram observados efeitos da interação entre os fatores adubação orgânica e boro, os efeitos dos dois fatores serão abordados em separado.

Efeito da adubação com vermicomposto de esterco de bovino

A adubação com $10 \mathrm{t} \mathrm{ha}^{-1}$ de vermicomposto de esterco de bovino resultou em aumento significativo de cerca $3,8 \mathrm{t} \mathrm{ha}^{-1}(6,7 \%)$ na produção de repolho, e de 170 gramas $(7,6 \%)$ e 0,8 $\mathrm{cm}(4,4 \%)$, respectivamente, no peso e no diâmetro das cabeças (Tabela 1). Com a aplicação de $10 \mathrm{t} \mathrm{ha}^{-1} \mathrm{de}$ vermicomposto foram fornecidos mais $110 \mathrm{~kg} \mathrm{ha}^{-1}$ de N, 30 de P, de K e de $\mathrm{Mg}$, 70 de $\mathrm{Ca}, 0,1$ de $\mathrm{B}, 1,6$ de $\mathrm{Cu}, 7,4$ de $\mathrm{Mn}$ e 2,0 de $\mathrm{Zn}$. Considerando que os teores dos micronutrientes $\mathrm{Cu}, \mathrm{Fe}, \mathrm{Mn}$ e $\mathrm{Zn}$ existentes originalmente no solo eram altos, que a quantidade de boro fornecida pela adubação com vermicomposto foi pequena e não afetou o teor de boro nas folhas do repolho (Tabela 1), e que a produção aumentou com o vermicomposto em todas as doses de boro, o efeito do adubo orgânico deve estar mais relacionado ao fornecimento extra de macronutrientes, à forma de liberação lenta que maximiza o aproveitamento pela planta e, também, a uma provável melhoria nas características físicas e na atividade biológica do solo. Oliveira et al. (2001), em um solo com 11,3 $\mathrm{g} \mathrm{dm}^{-3}$ de matéria orgânica, também com aplicação de $10 \mathrm{t} \mathrm{ha}^{-1}$ de vermicomposto de esterco de bovino, sem a utilização de adubação química, obtiveram uma produção de $32 \mathrm{t}$ $\mathrm{ha}^{-1}$ de cabeças de repolho, $10 \mathrm{t} \mathrm{ha}^{-1} \mathrm{a}$ mais do que no tratamento não adubado. Souza e Ferreyra H. (1996), em Areia Quartzosa Distrófica, com aplicação de $30 \mathrm{t} \mathrm{ha}^{-1}$ de esterco de bovino, obtiveram aumento de $54,3 \%$ no peso da cabeça comercial do híbrido Midori.

Embora não tenha sido observado aumento do teor de boro nas folhas, com a aplicação do vermicomposto (Tabela 1), o teor no solo aumentou. Os adubos orgânicos normalmente são pobres em boro e quando se compara apenas os tratamentos sem boro, com e sem adubação orgânica, não se observa variação na concentração do nutriente no solo. 
Aumento significativo, contudo, pode ser observado nos tratamentos que receberam adubação com boro, o que é indicativo de que a adubação orgânica tem efeito indireto na disponibilidade. De acordo com Stevenson (1991), o boro pode formar complexos com a matéria orgânica do solo que, ao serem mineralizados pelos microorganismos, liberam o boro em formas disponíveis para as plantas.

\section{Efeito da adubação com boro}

A adubação com boro não apresentou efeito no diâmetro das cabeças de repolho (Tabela 1) e a relação entre o peso de uma cabeça e a adubação com boro foi linear $(y=2,200+0,026 x)$, mas o valor de $R^{2}=0,331^{*}$, foi baixo.

A produtividade obtida variou de 52,94 a $65,95 \mathrm{t} \mathrm{ha}^{-1}$ e está muito acima da média citada por Trani et al. (1997) para o estado de São Paulo, que é de $33,4 \mathrm{tha}^{-1}$.

Como reflexo do aumento no peso das cabeças a produção aumentou linearmente com a quantidade de boro aplicada ao solo (Figura 1 ). $\mathrm{O}$ valor de $\mathrm{R}^{2}$ foi baixo, pois a variabilidade da produtividade é alta. Esta variabilidade, apesar do experimento ter sido feito em blocos ao acaso, em área admitida como homogênea com base em critérios visuais e no histórico de uso, pode estar relacionada à variação em outros atributos de fertilidade do solo que podem ter efeito mais pronunciado na definição da resposta de produção do repolho que o próprio boro. Mesmo o $\mathrm{R}^{2}$ sendo baixo, o valor do teste F para o modelo linear ajustado foi significativo ao nível de $1 \%$ de probabilidade, o que indica que há potencial para resposta do repolho à aplicação de doses até de $8 \mathrm{~kg}$ ha $^{-1}$ de B. Esta dose é o dobro da maior recomendação para repolho no estado de São Paulo (Trani e Raij, 1996). Considerando que o experimento foi instalado em área com teor médio de boro no solo $\left(0,26 \mathrm{mg} \mathrm{dm}^{-3}\right)$ e que a diferença de produção entre o tratamento que não recebeu $\mathrm{B}$ e o que recebeu $8 \mathrm{~kg} \mathrm{ha}^{-1}$ foi de aproximadamente $10 \mathrm{t} \mathrm{ha}^{-1}$ (cerca de $19 \%$ ), tem-se que o potencial do repolho para responder à adubação com boro é alto. Carneiro et al. (1985) obtiveram efeito da adubação com boro para repolho apenas nos tratamentos sem aduba-

Tabela 1. Produção, diâmetro e distribuição de plantas de repolho por classe de peso em função de doses de boro e adubação orgânica com vermicomposto de esterco de curral. Jaboticabal, UNESP, 2001.

\begin{tabular}{|c|c|c|c|c|c|c|}
\hline \multirow{2}{*}{$\begin{array}{c}\text { Boro } \\
\left(\mathrm{kg} \mathrm{ha}^{-1}\right)\end{array}$} & \multirow{2}{*}{$\begin{array}{c}\text { Vermicom- } \\
\text { posto }^{1} \\
\left(\mathrm{t} \mathrm{ha}^{-1}\right)\end{array}$} & \multicolumn{2}{|c|}{ Boro } & \multirow{2}{*}{$\begin{array}{l}\text { Produção } \\
\left(\mathrm{t} \mathrm{ha}^{-1}\right)\end{array}$} & \multicolumn{2}{|c|}{ Cabeça } \\
\hline & & $\begin{array}{c}\text { Folha } \\
\left(\mathrm{mg} \mathrm{kg}^{-1}\right)\end{array}$ & $\begin{array}{c}\text { Solo } \\
\left(\mathrm{mg} \mathrm{dm}^{-3}\right)\end{array}$ & & Peso (kg) & $\begin{array}{l}\text { Diâmetro } \\
\text { (kg) }\end{array}$ \\
\hline 0 & 0 & 28 & 0,24 & 52,94 & 2,12 & 18,0 \\
\hline 2 & 0 & 38 & 0,54 & 56,00 & 2,24 & 18,0 \\
\hline 4 & 0 & 41 & 1,09 & 53,81 & 2,11 & 17,8 \\
\hline 6 & 0 & 44 & 0,92 & 56,02 & 2,24 & 18,4 \\
\hline 8 & 0 & 42 & 2,00 & 62,33 & 2,37 & 18,8 \\
\hline Média $^{1}$ & & $39 a$ & $0,96 b$ & $56,22 \mathrm{~b}$ & $2,22 \mathrm{~b}$ & $18,2 b$ \\
\hline 0 & 10 & 23 & 0,26 & 55,87 & 2,23 & 18,2 \\
\hline 2 & 10 & 37 & 0,89 & 63,52 & 2,54 & 19,5 \\
\hline 4 & 10 & 40 & 1,16 & 57,62 & 2,27 & 18,5 \\
\hline 6 & 10 & 42 & 1,65 & 56,94 & 2,26 & 18,7 \\
\hline 8 & 10 & 43 & 2,33 & 65,95 & 2,64 & 19,9 \\
\hline \multirow[t]{2}{*}{ Média $^{1}$} & & $37 \mathrm{a}$ & $1,26 a$ & $59,98 a$ & $2,39 a$ & $19,0 a$ \\
\hline & & & & Teste F & & \\
\hline \multicolumn{2}{|l|}{ Boro (B) } & $8,53^{* *}$ & $20,51^{* *}$ & $6,72^{* *}$ & $4,29^{*}$ & $1,94 \mathrm{~ns}$ \\
\hline \multicolumn{2}{|c|}{ Vermicomposto (VC) } & $0,36 \mathrm{~ns}$ & $4,52^{* *}$ & $7,78^{*}$ & $7,99^{*}$ & $5,87^{*}$ \\
\hline \multicolumn{2}{|l|}{$B \times V C$} & $0,18 \mathrm{~ns}$ & $0,82 \mathrm{~ns}$ & $0,63 \mathrm{~ns}$ & $0,70 \mathrm{~ns}$ & $0,64 \mathrm{~ns}$ \\
\hline \multicolumn{2}{|l|}{$\overline{C V(\%)}$} & 16,2 & 34,9 & 6,4 & 7,2 & 4,7 \\
\hline
\end{tabular}

${ }^{1}$ Médias seguidas por letras iguais, na coluna, não diferem entre si pelo teste de Tukey a 5\% de probabilidade.

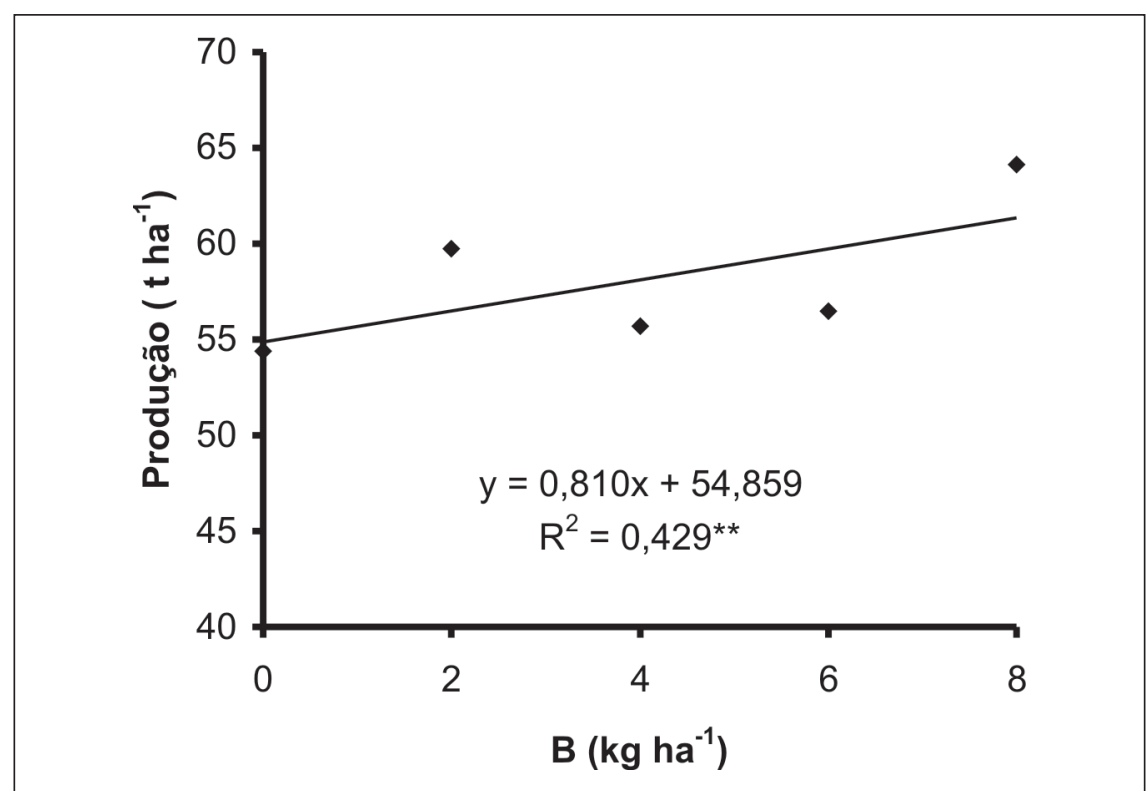

Figura 1. Produção de repolho em função de doses de boro. Jaboticabal, UNESP, 2001.

ção orgânica. No presente estudo, os efeitos das adubações orgânica e com boro foram complementares, de modo que, na média das doses de B, a adubação orgânica resultou em aumento de produção de 3,9 t ha-1. Alvares et al. (1985) avaliaram a resposta de repolho, híbrido Matsukaze, à aplicação de $0 ; 1$;
3; 5 e $10 \mathrm{~kg} \mathrm{ha}^{-1}$ de B, em LATOSSOLO VERMELHO-AMARELO com 0,38 $\mathrm{mg} \mathrm{kg}^{-1}$ de B extraído com água quente, e observaram que para atingir a produção máxima $\left(44,5 \mathrm{t} \mathrm{ha}^{-1}\right)$ foram necessários 7,18 kg ha-1 de B. Contudo, Gupta e Cutcliffe (1984) não obtiveram resposta de repolho à aplicação de até $8,8 \mathrm{~kg}$ 


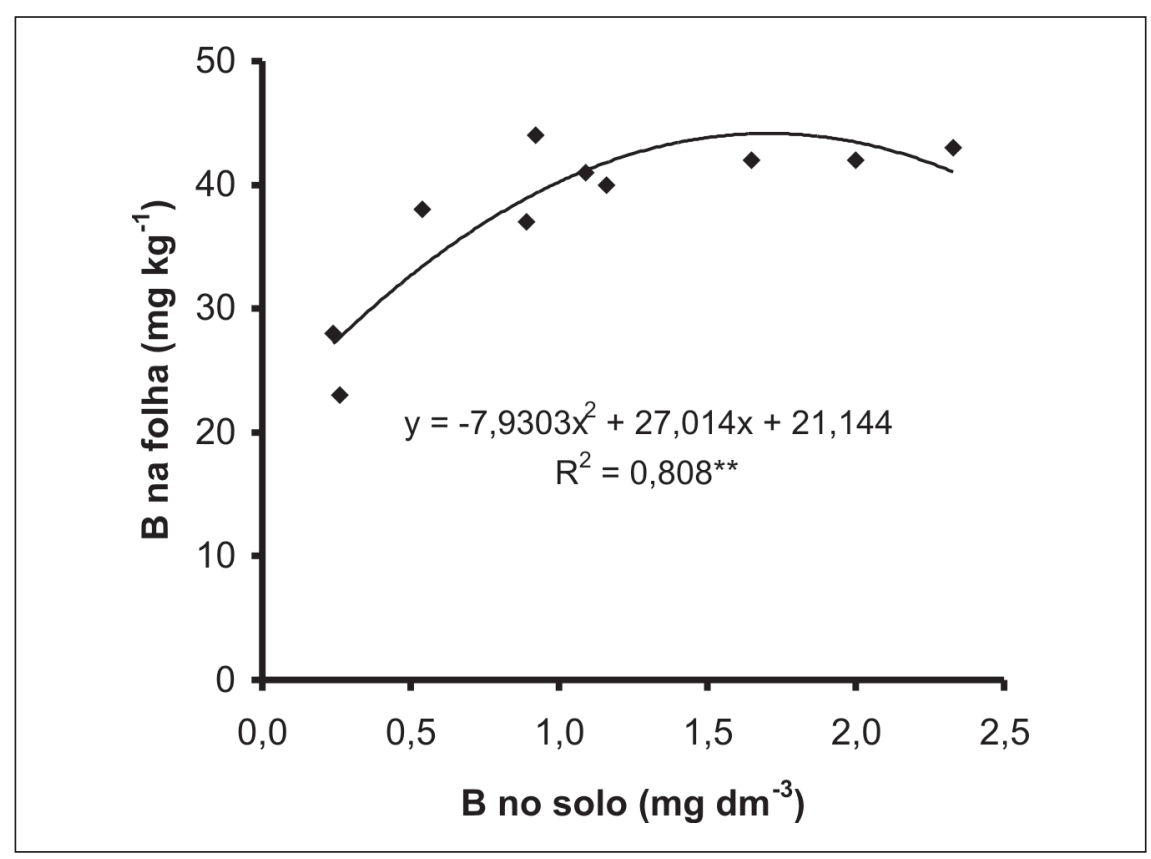

Figura 2. Concentração de boro na folha envoltória de repolho em função de teores no solo. Jaboticabal, UNESP, 2001.

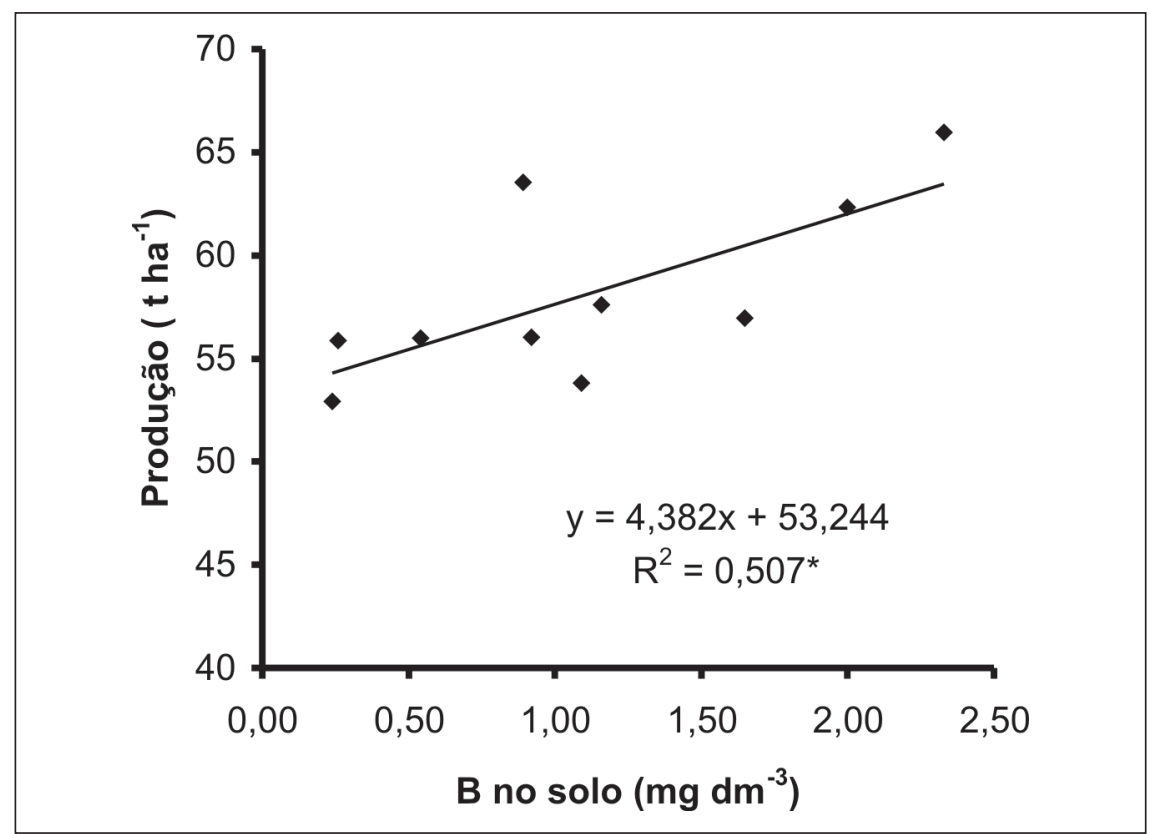

Figura 3. Produção de repolho em função de teores de boro no solo. Jaboticabal, UNESP, 2001.

ha $^{-1}$ de B, em ensaios de campo instalados em quatro locais, com teores de B solúvel em água quente entre 0,3 e 0,5 $\mathrm{mg} \mathrm{kg}{ }^{-1}$. Citando Lent e Scarchuk (1954), Gupta e Cutcliffe (1984) mencionam que redução na produção de repolho deve ser esperada com aplicação de cerca de $20 \mathrm{~kg} \mathrm{ha}^{-1}$ de B. No entanto, Coutinho et al. (1999) verificaram que a máxima produção foi obtida com $4 \mathrm{~kg}$
RAIJ, 1996). Contudo, não foi observado sintoma visual de deficiência. O efeito das doses de boro na concentração nas folhas foi quadrático $\left(\mathrm{y}=-0,446 \mathrm{x}^{2}\right.$ $\left.+5,521 \mathrm{x}+26,829, \mathrm{R}^{2}=0,970 * *\right)$, sendo que o máximo foi atingido com 6,2 $\mathrm{kg} \mathrm{ha}{ }^{-1}$ de B.

A relação entre teor de $\mathrm{B}$ nas folhas e produção do repolho não foi significativa. Este fato ocorreu, possivelmente, em virtude do teor de boro na folha ter praticamente estabilizado com a aplicação da menor dose de B (2 kg ha ${ }^{-1}$ de B). Alvares et al. (1985) obtiveram uma relação quadrática entre teor de boro nas folhas novas coletadas aos 60 dias após o transplantio e a produção relativa de repolho Matsukaze, sendo de 24,4 e 38, 2 $\mathrm{mg} \mathrm{kg}^{-1}$ os teores que corresponderam a 85 e $100 \%$ desta produção.

O teor de boro nas amostras de solo coletadas na linha de plantio, após a colheita do repolho, variou de 0,24 a $2,33 \mathrm{mg} \mathrm{dm}^{-3}$ (Tabela 1). A relação entre as doses aplicadas e os teores obtidos no solo foi linear $(y=0,22 x+0,23$, $\left.\mathrm{R}^{2}=0,949 * *\right)$. No trabalho de Alvares et al. (1985) o teor de boro no solo extraído com água quente chegou a cerca de $1,6 \mathrm{mg} \mathrm{kg}^{-1}$ com a aplicação de $10 \mathrm{~kg}$ ha $^{-1}$ de B e a relação entre dose aplicada e teor no solo foi quadrática, com o máximo teor no solo sendo atingido com aplicação de $7 \mathrm{~kg} \mathrm{ha}^{-1}$ de B.

Na Figura 2 tem-se a relação entre boro no solo e na folha envoltória, que demonstra um teor máximo na folha com 1,7 $\mathrm{mg} \mathrm{dm}^{-3}$ de B no solo, sendo que o melhor ajuste foi o quadrático $\left(\mathrm{R}^{2}\right.$ $\left.=0,808^{* *}\right)$. A estabilização dos teores na folha com as maiores doses de boro foi o aspecto determinante do comportamento quadrático.

A relação entre boro no solo e produção foi melhor explicada pelo modelo linear crescente (Figura 3). Alvares et al. (1985), por outro lado, obtiveram relação quadrática entre boro no solo extraído com água quente e produção relativa de repolho e $1,5 \mathrm{mg} \mathrm{kg}^{-1}$ de $\mathrm{B}$ no solo foi suficiente para atingir $100 \%$ de PR.

Os resultados obtidos permitem concluir que a aplicação de vermicomposto de esterco de bovino na linha de plantio resulta em ganho significativo na produtividade de repolho, mesmo em solo 
de boa fertilidade e com alto teor de matéria orgânica. Com um teor de B no solo de até $2,5 \mathrm{mg} \mathrm{dm}^{-3}$, o qual foi obtido com a aplicação de $8 \mathrm{~kg} \mathrm{ha}^{-1} \mathrm{de} \mathrm{B}$, se obteve uma relação linear crescente com a produção de repolho. O uso de doses de B mais elevadas poderiam ensejar a obtenção de uma relação quadrática e, desta, se estimar a produção máxima.

\section{AGRADECIMENTOS}

À FAPESP pelo financiamento do presente projeto.

\section{LITERATURA CITADA}

ABREU, C.A.; ABREU, M.F.; RAIJ, B.; BATAGLIA, O.C.; ANDRADE, J.C. Extraction of boron from soil by microwave heating for ICPAES determination. Communications in Soil Science and Plant Analysis, v.25, p.3321-3333, 1994.

ALVARES, M.C.; OLIVEIRA, S.A.; MATTOS, J.K.; MESQUITA FILHO, M.V. Resposta de repolho a adubação com bórax. Horticultura Brasileira, Brasília, v.3, p.18-21, 1985.

BATAGLIA, O.C.; FURLANI, A.M.C.; TEIXEIRA, J.P.F.; FURLANI, P.R.; GALLO, J.R Métodos de análise química de plantas. Campinas: Instituto Agronômico, 1983. 48 p. (Boletim técnico, 78)

CANTARELLA, H.; PROCHNOW, L.I. Determinação de sulfato em solos. In: RAIJ, B.; ANDRADE, J.C.; CANTARELLA, H.; QUAGGIO, J.A. (Ed.) Análise química para avaliação da fertilidade de solos tropicais. Campinas: Instituto Agronômico, 2001. p.225-230.
CARNEIRO, I.F.; ALMEIDA NET, J.X.; NAVES, R.V.; CHAVES, L.J. Efeito de diferentes níveis de boro, na presença e ausência de matéria orgânica, na cultura do repolho (Brassica oleracea var capitata). Horticultura Brasileira, Brasília, v.3, p.65, 1985. Trabalho apresentado no $25^{\circ}$ Congresso Brasileiro de Olericultura, 1985.

COUTINHO, E.L.M.; NATALE, W.; NISHIKAWA, M.A.N.; CASTELLANE, P.D Efeitos da calagem e da adubação com boro na produção e no estado nutricional das plantas de repolho. In: CONGRESSO BRASILEIRO DE CIÊNCIA DO SOLO, 27.,1999, Brasília. Anais... Brasília: SBCS, 1999. CD-ROM

DIXIT, H.C.; SINGH, V. Effect of boron and calcium on yield and nutrition of cabbage (Brassica oleracea convar capitata var capitata) in Ustipsamment. Indian Journal of Agricultural Sciences, v.67, p.87-88, 1997.

GUPTA , U.C.; CUTCLIFFE, J.A. Effects of applied and residual boron on the nutrition of cabbage and field beans. Canadian Journal of Soil Science, v.64, p.571-576, 1984.

KIEHL, E.J. Fertilizantes orgânicos. Piracicaba: Ceres, 1985. 492 p.

LINDSAY, W.L.; NORVELL, W.A. Development of a DTPA soil test for zinc, iron, manganese, and copper. Soil Science Society of America Journal, v.42, p.421-428, 1978.

MARTENS, D.C.; WESTERMANN, D.T Fertilizer applications for correcting micronutrient deficiencies. In: MORTVEDT, J.J.; COX, F.R.; SHUMAN, L.M.; WELCH, R.M. (Ed.) Micronutrients in agriculture. 2. ed. Madison: Soil Science Society of America, 1991. p.549-592. OLIVEIRA, A.P.; FERREIRA, D.S.; COSTA, C.C.; SILVA, A.F.; ALVES, E.V. Uso de esterco de bovino e húmus de minhoca na produção de repolho híbrido. Horticultura Brasileira, Brasília, v.19, p.70-73, 2001.
RAIJ, B.; QUAGGIO, J.A.; CANTARELLA, H.; FERREIRA, M.E.; LOPES, A.S.; BATAGLIA, O.C. Análise química de solo para fins de fertilidade. Campinas: Fundação Cargill, 1987. 170 p. SOUZA, M.C.M.R.; FERREYRA H., F.F. Efeitos da calagem, matéria orgânica e níveis de boro na cultura do repolho, híbrido Midori, cultivado em Areias Quartzosas distróficas. In: CONGRESSO LATINO AMERICANO DE CIÊNCIA DO SOLO, 13.,1996, Águas de Lindóia. Anais... Águas de Lindóia: SBCS, 1996. CD-ROM

STEVENSON, F.J. Organic matter-micronutrient reactions in soil. In: MORTVEDT, J.J.; COX, F.R.; SHUMAN, L.M.; WELCH, R.M. (Ed.) Micronutrients in agriculture. 2. ed. Madison: Soil Science Society of America, 1991. p.145-186. TEDESCO, M.J.; VOLKWEISS, S.J.; BOHNEN, $\mathrm{H}$. Análises de solo, plantas e outros materiais. Porto Alegre: UFRGS, 1985. s.p. (Boletim técnico, 5)

TRANI, P.E.; GROPPO, G.A.; SILVA, M.C.P.; MINAMI, K.; BURKE, T.J. Diagnóstico sobre a produção de hortaliças no Estado de São Paulo. Horticultura Brasileira, Brasília, Brasília, v.15, p.19-24, 1997.

TRANI, P.E.; RAIJ, B. Hortaliças. In: RAIJ, B.; CANTARELLA, H.; QUAGGIO, J.A.; FURLANI, A.M.C. (Ed.) Recomendações de adubação e calagem para o Estado de São Paulo. Campinas: Instituto Agronômico/Fundação IAC, 1996. p.157-164. (Boletim técnico, 100)

TRANI, P.E.; PASSOS, F.A.; AZEVEDO, J.A.; TAVARES, M. Brócolos, couve-flor e repolho. In: RAIJ, B.; CANTARELLA, H.; QUAGGIO, J.A.; FURLANI, A.M.C. (Ed.) Recomendações de adubação e calagem para o Estado de São Paulo. Campinas: Instituto Agronômico/Fundação IAC, 1996. p.175. (Boletim técnico, 100). 